This item was submitted to Loughborough's Research Repository by the author.

Items in Figshare are protected by copyright, with all rights reserved, unless otherwise indicated.

\title{
A new look at economic convergence in Europe: a common factor approach
}

PLEASE CITE THE PUBLISHED VERSION

LICENCE

CC BY-NC-ND 4.0

\section{REPOSITORY RECORD}

Becker, Bettina, and Stephen G. Hall. 2019. "A New Look at Economic Convergence in Europe: A Common Factor Approach". figshare. https://hdl.handle.net/2134/2747. 
This item was submitted to Loughborough's Institutional Repository by the author and is made available under the following Creative Commons Licence conditions.

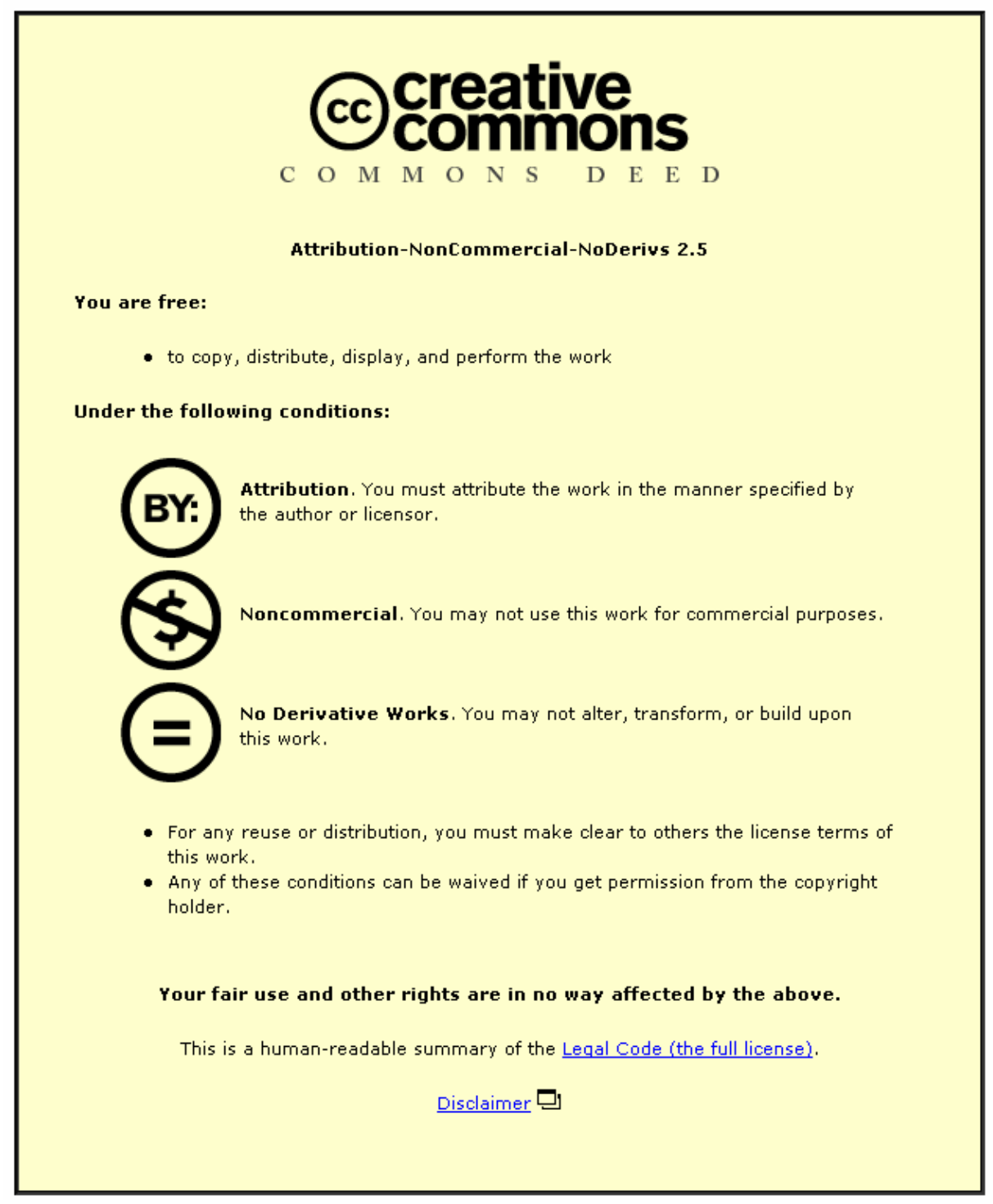

For the full text of this licence, please go to: http://creativecommons.org/licenses/by-nc-nd/2.5/ 
ISSN 1750-4171

\title{
DEPARTMENT OF ECONOMICS
}

\author{
DISCUSSION PAPER SERIES
}

\section{A New Look at Economic Convergence in Europe: $A$ Common Factor Approach}

\author{
Bettina Becker and Stephen G. Hall
}

WP 2007 - 09 


\title{
A New Look at Economic Convergence in Europe: A Common Factor Approach
}

\author{
Bettina Becker $^{\mathrm{a}}$ and Stephen G. Hall ${ }^{\mathrm{b}}$
}

\author{
March 2007
}

\begin{abstract}
We propose a common factor approach to analyse convergence, which we implement using principal components analysis. We show that this method provides a useful new way of approaching the convergence debate. We apply this technique to a dataset of nominal and real monthly exchange rates of the twelve member countries of the European Monetary Union over the period 1970-2001. Our empirical results neatly capture the convergence patterns related to the various regimes from Bretton Woods toward EMU. The UK's Pound Sterling has been on a gradual convergence path to the Euro, although convergence is less progressed than it was for the EMU countries by 1999.
\end{abstract}

\section{JEL classification: C22, F31}

Keywords: Convergence, exchange rates, European Monetary Union, nominal convergence, real convergence, principal components analysis.

a (Corresponding author) Loughborough University. Address: Department of Economics, Loughborough University, Loughborough, LE11 3TU, UK. Tel.: +44 (0)1509 222719, fax: +44 (0)1509 223910, e-mail: b.becker@lboro.ac.uk.

${ }^{b}$ University of Leicester and National Institute of Economic and Social Research, London. Address: Department of Economics, University of Leicester, University Road, Leicester, LE1 7RH, UK. Tel.: +44 (0)116 252 2827, fax: +44 (0)116 252 2908, e-mail: s.g.hall@le.ac.uk. 


\section{Introduction}

The enlargement of the European Union by ten Eastern European economies in May 2004 and the distinct characteristics of the European Monetary Union (EMU) member countries keep the issue of convergence prominent in the academic and policy debate. However the very notion of convergence quickly becomes problematic from an academic viewpoint when we try and formalise a framework to think about these issues. This is despite the fact that convergence has been a popular theme in applied economics since the seminal papers of Barro (1991) and Barro and Sala-i-Martin (1992). In this paper we consider some of the standard definitions of convergence and suggest an alternative way to think about convergence based on a common factor framework which we implement using principal components analysis. We apply these ideas to a dataset of monthly nominal and real exchange rates of the twelve EMU member countries over the period 1970-2001. We argue that this common factor framework provides a useful new way of approaching the convergence debate.

We first consider the notion of convergence and show how a common factor approach to the problem is in many ways a more natural way to think of things than those conventionally used. Our empirical results neatly capture the different convergence patterns related to the various regimes of the European Monetary System (EMS), including the Exchange Rate Mechanism (ERM), as well as the introduction of fixed conversion rates of national currencies to the Euro in 1999 and for Greece in 2001. Individual country experiences, such as the consequences of the 1992 speculative attack for the Italian exchange rate, are also reflected in the results. The results stand up when principal components analyses are conducted over each of the three decades of the investigation period as well as over each semi-decade. A subsequent split of these more 'neutral' time periods into sub-periods as 
determined by the various regimes of the EMS corroborates the results and yields additional insights. A comparative investigation of the UK's exchange rate path suggests that the Pound Sterling has been on a gradual convergence path to the Euro over the past few years, although convergence is less progressed than it was for the EMU countries on inception of the currency union in 1999.

The paper is structured as follows. Section 2 considers the notion of convergence and shows how a common factor approach is a useful new and in many ways more natural framework for defining convergence. Section 3.1 presents the empirical results for the twelve EMU member countries, and section 3.2 considers the UK experience. Section 4 concludes.

\section{Defining Convergence}

While we have a clear idea regarding the importance of convergence as a pre-requisite for economic changes such as the formation of a monetary union and we have a clear intuitive understanding of what convergence means, it is surprisingly difficult to find a satisfactory formal definition of convergence. Hall, Robertson and Wickens (1997) consider a number of formal definitions of convergence which illustrate the difficulty here. So consider the pointwise convergence of two series $X_{t}$ and $Y_{t}$ which we might define as occurring when,

$$
\lim _{t \rightarrow \infty}\left(X_{t}-\phi Y_{t}\right)=\alpha
$$

where $\alpha$ is a non stochastic constant which might often be required to be zero. This is a clear definition of convergence but it is unrealistically strong as it requires the two series to exactly move together in the limit. A more reasonable definition would be to think of stochastic convergence or convergence in expectations 
$\lim E\left(X_{t}-\phi Y_{t}\right)=\alpha$

$t \rightarrow \infty$

This at first seems like a reasonable definition of convergence but the problem here is that it implies convergence in many quite unreasonable cases. For example if $\mathrm{X}$ and $\mathrm{Y}$ are both mean zero white noise processes then this definition would suggest that the two series are converged even though they have no relationship. If $\mathrm{X}$ and $\mathrm{Y}$ are non-stationary then sensible definitions may be offered through the notion of cointegration and the idea that convergence may limit the difference between the two series to a stationary difference either in the limit or over a given interval. However while this is a useful operational notion of convergence again it is limited by only being useful in the case of non-stationary series.

Here we propose a general measure of convergence which is based around the common factor representation of a group of series and which we believe more closely follows the basic conceptual idea which we have in mind when we talk about convergence. Consider a vector of 2 or more variables $X$ which are determined by a set of factors $F$

$x_{i t}=\lambda_{i} f_{i t}$

Then we may give the following definition of when $\mathrm{X}$ are converged.

Definition 1: The set of variables $\mathrm{X}$ are converged when the general factor representation in (3) may be restricted to the single common factor model given by,

$x_{i t}=\lambda_{i} f_{t}+\varepsilon_{i t}$ 4.

and $\lambda_{i} \neq 0$ for all $i$

where $\varepsilon_{t}$ are $\mathrm{N}$ specific factors. 
The conventional assumption is that $\mathrm{f}_{\mathrm{t}}$ and $\varepsilon_{t}$ are uncorrelated across all $\mathrm{i}$ and $\mathrm{t}$ and as Anderson (1963) pointed out this is unlikely to be true of time series data, which is the primary interest here. Geweke (1977) however generalised this model to produce the dynamic factor model in the following way. The assumption is made that $\mathrm{f}_{\mathrm{t}}$ and $\varepsilon_{t}$ are strictly indeterministic and covariance stationary, which of course allows them to have a constant, time invariant correlation structure. Then by Wolds (1938) theorem there exist two sets of white noise terms $\mathrm{z}$ and $\mathrm{u}_{\mathrm{i}}$ such that

$$
\lambda_{i} f_{t}=\sum_{s=0}^{\infty} a_{i s} z_{t-s}=a_{i}^{*} z_{t}
$$

and

$$
\varepsilon_{i t}=\sum_{s=0}^{\infty} b_{i t s} u_{i t-s}=b_{i t}^{*} u_{i t}
$$

hence

$$
x_{t}=a^{*} z_{t}+b^{*} u_{t}
$$

where $\mathrm{b}$ is a diagonal matrix and the variances of $\mathrm{z}$ and $\mathrm{u}$ are normalised to be unity. This is then the dynamic single factor model. This model is a straightforward representation of one notion of what we mean by convergence. All the elements of $X$ are moving in a similar way although they do each have an idiosyncratic element, as the elements of $b^{*}$ go to zero the common feature completely dominates the behaviour of $\mathrm{x}$ and variables move perfectly together.

Of course not all series will satisfy the conditions for the decomposition in (7) and so Geweke (1977) proposes a formal test of this structure based on the restrictions to the 
covariance structure of $\mathrm{X}$ implied by (7). This test works both for individual intervals in the frequency domain $\left(\omega_{1}{ }^{j}, \omega_{2}{ }^{j}\right], \mathrm{j}=1 \ldots \mathrm{p}$ and a joint test for all the intervals. Of course in the context of convergence the problem with this test is, that like many other tests, it may not detect a process of developing convergence as it is designed to detect complete convergence over the entire sample being tested.

To consider this process of gradual convergence we can return to the general factor model (3)

$$
x_{i t}=\lambda_{i} f_{i t}
$$

and define the factors to be orthogonal to each other. If the factors are then ordered so that the first factor is calculated to have the maximum explanatory power, the second factor has the next highest power and so on (as in a principal components analysis) then the notion of on going convergence becomes rather straightforward. Pointwise convergence, as defined above would imply that in the limit the first factor would be a complete explanation of $\mathrm{X}$ and so all the factors other than the first one would be zero. This would then collapse to the single factor model (7) where $b=0$. Convergence in expectations would imply that the expected value of all the factors except the first one would be zero and again in terms of (7) this would mean that the single factor model be accepted but the $b$ would not be restricted to zero. However in a practical sense the usefulness of this approach becomes more obvious when we realise that there is a direct measure of the degree of convergence between the series in the form of the $\% \mathrm{R}^{2}$ of the first factor. This shows the $\%$ of the total variation of $\mathrm{X}$ which is explained by the first factor. Pointwise convergence would imply that this is 1 and in general the closer this is to 1 the more complete is convergence between the set of series. This then allows us to deal with the problem of using convergence in expectations. Consider the case of n, mean zero IID distributed series; the expectation of the difference between these series on 
a pairwise basis would be zero so they would all meet the condition for convergence in expectation, despite the fact that they are completely unrelated to each other. However in the factor representation the $\% \mathrm{R}^{2}$ for the first factor would be $1 / \mathrm{n}$ as each factor would have equal explanatory power. The single factor model would be rejected and this would indicate that there was no common underlying driving force linking the $\mathrm{n}$ series together. If the series began to move together then the explanatory power on the first factor would rise and so this becomes a natural metric for the extent to which convergence has occurred.

Definition 2: Convergence is taking place between a vector of 2 or more series over any given period 1 to $\mathrm{T}$ if the $\% \mathrm{R}^{2}$ of the first principle component calculated over the period 1 to $\mathrm{T} / 2$ is less than the $\% \mathrm{R}^{2}$ of the first principal component calculated over the period $\mathrm{T} / 2$ to $\mathrm{T}$.

This approach also works regardless of the Stationarity properties of the data. So in the I(1) case, if we have pairwise cointegration between the set of series so that between the $\mathrm{n}$ series there are $n-1$ cointegrating vectors then in ECM form the model may be written as

$\gamma(L)(1-L) X_{t}=\Pi X_{t-1}+v+\varepsilon_{t}$

where $\Pi$ has rank $\mathrm{n}-1$ and $v$ is the deterministic component.

The moving average equivalent of this is

$(1-L) X_{t}=C(L)\left(\varepsilon_{t}+v\right)$

and the $\mathrm{C}$ matrix may be decomposed into

$(1-L) X_{t}=C(1)\left(\varepsilon_{t}+v\right)+(1-L) C^{*}(L)\left(\varepsilon_{t}+v\right)$

where $C(1)$ has rank 1 and so there will be one common stochastic trend which is the dominant first factor in the factor representation. Asymptotically as the variance of this non 
stationary trend will dominate any stationary terms the $\% \mathrm{R}^{2}$ will go to one and convergence in expectation is clear. Over a small sample the size of the $\% \mathrm{R}^{2}$ will be an indicator of how important the common stochastic trend is relative to the noise in the series, again it becomes a direct measure of how much convergence has taken place. If any factor other than the first one shows signs of non Stationarity then this would imply less than n-1 cointegrating vectors and hence full pairwise cointegration would not exist.

\section{Empirical Application}

In this section we apply the common factor approach we propose in section 2 to a dataset of nominal and real exchange rates of the current twelve EMU member countries over the period 1970-2001. The US-Dollar is used as the reference currency. The time dimension of our dataset spans 32 years of monthly data, so it includes all stages of the development process towards EMU since the breakdown of the Bretton Woods System in 1971; the inception of the ERM of the EMS in 1979, the crisis in 1992 that led to the breakdown of the ERM, as well as the introduction of fixed conversion rates of national currencies to the Euro for eleven of the twelve EMU countries in 1999 and for Greece in 2001. The data were taken from the International Financial Statistics of the IMF. ${ }^{1}$

We begin by confirming the result that convergence does not exist for the 12 member states over the whole period either for nominal nor real exchange rates. The Geweke Test for a single common factor over the whole period resoundingly rejects the single factor representation for both real and nominal rates. The test statistic is 186.2 for nominal rates and 176.4 for real rates (the $5 \%$ critical value is approximately 124 ). So there is clearly not

\footnotetext{
${ }^{1}$ From 1999, the Euro growth rate was linked onto national currencies to prevent a break in the series.
} 
complete convergence over the whole period. We then proceed to investigate the existence of a process of ongoing convergence.

We implement the common factor approach using principal components analysis on consecutive sub-periods of 1970-2001 and applying Definition 2 to identify gradual convergence processes over time. We first consider each decade within the sample period, followed by an application to semi-decades. We would expect to see increasing convergence of exchange rate movements in the run-up to the introduction of fixed rates in 1999 and pointwise convergence from this year except for the Greek Drachma. We compare nominal versus real convergence patterns, and we also look at the relative experience of the UK which recently decided not (yet) to join the single currency union. After looking at the 'neutral' time periods of ten- and five-year windows, we split the investigation period into sub-periods as determined by the various regimes of the EMS, which yields additional insights.

\subsection{Gradual Convergence Patterns of EMU Exchange Rates}

\subsubsection{Ten-year and five-year windows}

Table 1 presents the $\% \mathrm{R}^{2}$ of the first principal component of nominal and real exchange rates over the three decades 1970-79, 1980-89 and 1990-99. ${ }^{2}$ For comparison, we also include two more time periods, 1990-98 and 1990-2001, to exclude the first year of complete convergence of the EMU11 group and to include the first year of complete convergence of the EMU12 group, respectively. As we show in section 2 , the $\% \mathrm{R}^{2}$ of the first component gives us a direct measure of the degree of convergence and so when we compare the $\% \mathrm{R}^{2}$

\footnotetext{
${ }^{2}$ For neatness of the presentation, we present the $\mathrm{R}^{2}$ of the first principal component only. Full results are available upon request.
} 
over the consecutive time periods then by Definition 2 this allows us to identify processes of gradual convergence pattern of the European exchange rates over time.

Table 1a shows that exchange rates converged considerably between the 1970s and 1980s. This reflects the impact of the inception of the ERM on promoting convergence of nominal rates. Moreover, the period includes the first two years of the 'new' or 'hard' EMS, in which there were no realignments of exchange rates (February 1987 until mid-September 1992). ${ }^{3}$ Between 1980-89 and 1990-98 we observe exchange rate divergence, as indicated by a fall of the $\% \mathrm{R}^{2}$ so the other components gain more weight and exchange rate movements become more heterogeneous. This is in line with what we would expect in the light of the events that took place in the early 1990s: the breakdown of the ERM in 1992 and subsequent extension of the exchange rate margins in 1993 in order to accommodate monetary problems with the Italian Lira, hence reducing convergence requirements. Extending the 1990-98 window sequentially until the beginning of EMU12 in 2001 indicates the expected smoothing impact of the move to the single currency.

Table $1 \mathrm{~b}$ reports results for the five-year windows, which reflect these developments in more detail, in particular the divergence of exchange rates in the aftermath of the breakdown of the Bretton Woods System (1975-79 window), the impact of the inception of the ERM (1980-84 window) and its crisis (1990-94) as well as the subsequent movement towards EMU. The results illustrate that the ERM as well as the prospect of EMU may have helped to promote convergence in nominal exchange rates.

\footnotetext{
${ }^{3}$ The term 'new' EMS goes back to Giavazzi and Spaventa (1990). For analyses of the developments and the three stages of this period see for example Eichengreen and Wyplosz (1993) and Portes (1993).
} 
The factor model (8) also tells us if the individual countries have any pattern in terms of groups or clubs which have common effects. The weighting matrix $\lambda$ tells us how independently of each other the national currencies fluctuate around the reference currency. As we show in section 2, complete convergence would imply a vector of 1 's in the first columns of $\lambda$, i.e. in our case the country-specific weight of the first principal component would be one and the weight of all other components would be zero for each country. Therefore the closer the weights of the first principal component are to one for all countries or for a group of countries, the more the exchange rates of all countries, or of the group, move together.

Figure 1 presents the country-specific weights of the first principal component, where each row of graphs shows the results for the decade to the left of the results for the two corresponding semi-decades. The developments support the finding of overall gradual convergence through the three decades. As indicated by the $\% \mathrm{R}^{2}$ above, the heterogeneity of nominal exchange rate movements in 1970-79 mainly stems from the second half of the decade, and the weights show that Finland, Greece, Ireland, Italy, Portugal and Spain display substantially different patterns of exchange rate fluctuations than Austria, Belgium, France, Germany, Luxembourg and the Netherlands. The inception of the ERM in 1979 and the beginning of the 'new' EMS in 1987 are associated with much more homogeneous nominal exchange rate movements in the 1980s, with all weights now having the same sign for the decade as a whole. Moving to the 1990s, the results witness the crises experienced in Italy and Finland, as well as the disintegration and breakdown of the ERM as suggested by the decline in the weights for most countries between 1980-89 and 1990-98 and their substantial variance in 1990-94. We also observe the fact that the Italian Lira remained the laggard in terms of convergence of nominal exchange rates in the second half of the 1990s. Behind this lay the extension of the exchange rate margins to $15 \%$, which meant that less convergence 
was required to remain within the bands and which was in effect relevant only for the Lira, allowing Italy to return to the EMS. The results also highlight that in terms of exchange rates Greece had been more converged with the other countries than Italy, although because of other Maastricht criteria Greece was not amongst the founding members of EMU.

The country weights regarding real exchange rates are illustrated by the solid lines in Figure 1, and Tables $1 \mathrm{a}$ and $\mathrm{b}$ report the respective $\% \mathrm{R}^{2}$ of the first principal component. The results show that over the decades, real rates moved together more closely than nominal rates, again matching the historic evidence. Nominal exchange rates accommodated inflation differentials so that real rates were smoother than nominal ones. The period $1980-89$, for instance, saw five of the eleven realignments that took place between September 1979 - January 1987, reflecting the persistence of inflation differentials across EMS member countries. The first half of the 1990s incorporates two opposing developments; First, the abolition of capital controls for most countries in 1990, i.e. the removal of one means of support of exchange rates and second, self-fulfilling expectations of continued stability that tied down nominal rates at the beginning of the 1990s, until this support was removed by the shock of the speculative attacks of September 1992. For the period 1990-94 as a whole, the convergenceimpeding forces generally seem to outweigh the convergence-supporting forces (Table $1 \mathrm{~b}$, Figure 1). These can be disentangled from each other when we consider consecutive time periods as determined by the different stages of the EMS in the following section.

\subsubsection{EMS Regimes}

Table 1c reports the $\% \mathrm{R}^{2}$ of the first principal component when we divide the sample period into seven sub-periods as determined by the EMS regimes. When we apply Definition 2 to this sequence of periods we can capture gradual convergence related to the EMS stages in more detail than with the 'neutral' periods of ten- and five-year windows. 
The promotion of convergence through the inception of the ERM in March 1979 is brought out more clearly by the larger increase in the $\% \mathrm{R}^{2}(65 \%$ to $94 \%$ in Table $1 \mathrm{c}$ versus $67 \%$ to $81 \%$ in Table 1a). The divergence seen in the following period, February 1987 - June 1990, stemmed from problems with the Finnish, Greek, Portuguese and Spanish currencies, that is Finland and the group of countries that have often been called the 'periphery' of EMU, while convergence of the remaining exchange rates generally continued, as shown by the country weights in Figure 2c. For July 1990 - December 1991, i.e. from the elimination of capital controls until the end of the second stage of the 'new' EMS at the end of 1991 (Eichengreen and Wyplosz, 1993), the results show the strong convergence of nominal exchange rates that could be observed despite the persistence of inflation differentials and the absence of capital controls.

The disintegration of the ERM in 1992 is captured by the substantial fall of the $\% \mathrm{R}^{2}$ (Table 1c), and country-specific experiences are neatly reflected by the weights (Figure 2e). Indeed, the herds of the crisis, Italy and Finland, have the lowest weights, indicating that the convergence process was lagging behind here. As continued convergence relied on selfvalidating expectations of smooth transition to monetary union by monetary authorities and foreign exchange markets, convergence was prone to come to an abrupt halt once any external shock were to hit the system, such as the speculative attacks on the Italian (as well as the Finnish and British) currencies in September 1992. These forced Italy to withdraw from the ERM on 16 September, ${ }^{4}$ followed by involuntary devaluations of the Portuguese and Spanish currencies. Signs of recovery are seen in 1993. However, recovery proceeded slowly as Ireland as well as Portugal and Spain had to devalue their currencies in 1993 and exchange rate margins were expanded so as to accommodate for Italy's monetary difficulties. The

\footnotetext{
${ }^{4}$ The same applies to the UK, which is considered in the next section.
} 
results finally also picture the acceleration of convergence as the economies approached monetary union.

\subsection{The UK Experience}

In this section, we add the UK's exchange rate to the sample and apply the common factor approach to analyse the development of the UK's rate relative to those of the EMU economies. Table 2 reports the $\% \mathrm{R}^{2}$ of the first principal component, and Figure 3 presents the corresponding UK-specific weights. The weights for the EMU12 economies were essentially unchanged compared to those presented in Figure 1 and have therefore been excluded from Figure 3 for ease of exposition. ${ }^{5}$

Overall, adding the UK to the sample makes little difference in the early periods but slows convergence somewhat in 1990-1998 as a result of the effects of the ERM crisis on the UK and its subsequent drop-out, as might have been expected. The five-year sub-periods provide more detailed insight into the convergence pattern of the UK's exchange rate. The weights depicted in Figure $3 \mathrm{~b}$ compared to Figure 1 reflect the breaking of parity of the Pound Sterling with the Irish Pound when the UK declined to join the ERM in 1979: the UKspecific weight is identical to the Irish weight in the first half of the 1970s, but switches sign in the second half. From the beginning of the 1990s, the UK economy, as all ERM, came under significant inflationary pressure when the Bundesbank increased interest rates substantially after German re-unification in order to appreciate the DM in real terms without changing inflation. Similarly to the Italian experience, the problems related to interest rate policy added to the difficulties resulting from the UK's double deficit. In July 1992 the Pound began to weaken until the government was eventually not able to fend off speculative attack, forcing the UK out of the ERM on 16 September. The switch of sign of the weight 
shows that divergence of the UK gained momentum in the second half of the decade. Divergence is also indicated by the smaller $\% \mathrm{R}^{2}$ in this period compared to the EMU12 sample (Tables $1 \mathrm{~b}$ and $2 \mathrm{~b}$ ). This mirrors the fact that immediately after the UK had been forced to leave the ERM, the discount rate was cut by $50 \%$, and following a significant devaluation, the Pound Sterling traded below its former lower ERM band of 2.78 DM. After falling further to below 2.2 DM in April, Sterling then began to recover, as can again be witnessed in the results of the principal components analysis, although it remained below the ERM band until May 1997. The profile of the weights in the cluster-like time periods beginning in 1995 indicates gradual convergence of the UK's exchange rate. Even so, the rate of convergence has declined recently, and when expanding the period to 2003, the weight is still below $65 \%$. Hence while the UK's exchange rate appears to be gradually converging towards the Euro rate, convergence is still less progressed than it was for the EMU countries on forming the single currency union.

Finally, repeating the analysis for the EMS regimes shows that in 1992 the UK-specific weight lies between those of Italy and Finland (Figures 3c and 2e), hence the principal components analysis correctly identifies the three countries hit by speculative attack.

\section{Conclusion}

In this note we have proposed an alternative technique of approaching the convergence debate based on a common factor framework which we implement using principal components analysis. We have shown how this is in many ways a more natural way to consider the problem than those conventionally used. We have applied these ideas to a dataset of monthly nominal and real exchange rates of the twelve EMU member countries over the period 1970-2001. The results neatly capture the different convergence patterns

\footnotetext{
${ }^{5}$ Full results are available upon request.
} 
related to the various regimes from Bretton Woods toward EMU. This includes individual experiences of member countries, such as the consequences of the 1992 speculative attack for the Lira. Moreover, the results stand up over different time periods, such as decades and semi-decades as well as sub-periods as determined by the EMS regimes. A comparative analysis of the UK's exchange rate path suggests that the Pound Sterling has been on a gradual convergence path to the Euro over the past few years. However, convergence seems to be less progressed than it was for the EMU countries on forming the single currency union. We conclude that the common factor approach provides a useful new way of approaching the convergence debate and invites application to other facets of the convergence debate.

\section{References}

Anderson TW. The use of factor analysis in the statistical analysis of multiple time series. Psychometrica 1963; 28: 1-25.

Barro R. Economic Growth in a cross section of countries. Quarterly Journal of Economics 1991; 106: 407-443.

Barro R, Sala-i-Martin X. Convergence. Journal of Political Economy 1992; 100: 223-251.

Eichengreen B, Wyplosz C. The unstable EMS. Brookings Papers on Economic Activity 1993; 1: 51-143.

Geweke J. The dynamic factor analysis of economic time series models. Chapter 19 in Aigner D, Goldberger A (eds.). Latent Variables in Socioeconomic Models. North-Holland: Amsterdam, 1977; 365-383.

Giavazzi F, Spaventa L. The 'new' EMS. In De Grauwe P, Papademos L (eds.). The European Monetary System in the 1990s, Longman: New York, 1990; 65-85.

Hall SG, Robertson D, Wickens MR. Measuring Economic Convergence. International Journal of Finance and Economics 1997; 2: 131-143.

Portes R. EMS and EMU after the fall. The World Economy 1993; 16: 1-16. 
Table 1. Principal components analysis of exchange rates of the twelve EMU member countries ( $\% \mathrm{R}^{2}$ of first principal component)

a. 10-year windows

\begin{tabular}{l|l|l|lll}
\hline & $\mathbf{1 9 7 0 - 7 9}$ & $\mathbf{1 9 8 0 - 8 9}$ & $\mathbf{1 9 9 0 - 9 8}$ & $\mathbf{1 9 9 0 - 9 9}$ & $\mathbf{1 9 9 0 - 2 0 0 1}$ \\
\hline Nominal rates & 0.6680 & 0.8055 & 0.7118 & 0.7721 & 0.8966 \\
\hline Real rates & 0.7991 & 0.9014 & 0.7426 & 0.7979 & 0.9159 \\
\hline
\end{tabular}

b. 5-year windows

\begin{tabular}{l|ll|ll|llll}
\hline & $\mathbf{1 9 7 0 - 7 4}$ & $\mathbf{1 9 7 5 - 7 9}$ & $\mathbf{1 9 8 0 - 8 4}$ & $\mathbf{1 9 8 5 - 8 9}$ & $\mathbf{1 9 9 0 - 9 4}$ & $\mathbf{1 9 9 5 - 9 8}$ & $\mathbf{1 9 9 5 - 9 9}$ & $\mathbf{1 9 9 5 - 2 0 0 1}$ \\
\hline Nominal rates & 0.7308 & 0.5471 & 0.9801 & 0.8875 & 0.7247 & 0.9421 & 0.9600 & 0.9869 \\
\hline Real rates & 0.8779 & 0.6833 & 0.9693 & 0.9767 & 0.7285 & 0.9319 & 0.9539 & 0.9837 \\
\hline
\end{tabular}

c. EMS regimes

\begin{tabular}{l|l|l|l|l|l|l|l}
\hline & $\mathbf{0 1 / 7 0 - 0 2 / 7 9}$ & $\mathbf{0 3 / 7 9 - 0 1 / 8 7}$ & $\mathbf{0 2 / 8 7 - 0 6 / 9 0}$ & $\mathbf{0 7 / 9 0 - 1 2 / 9 1}$ & $\mathbf{0 1 / 9 2 - 1 2 / 9 2}$ & $\mathbf{0 1 / 9 3 - 1 2 / 9 3}$ & $\mathbf{0 1 / 9 4 - 1 2 / 9 8}$ \\
\hline Nominal rates & 0.6453 & 0.9382 & 0.8244 & 0.9629 & 0.7658 & 0.8343 & 0.9202 \\
\hline
\end{tabular}


Table 2. Principal components analysis of exchange rates of the twelve EMU member countries plus UK

$$
\left(\% \mathrm{R}^{2}\right. \text { of first principal component) }
$$

a. 10-year windows

\begin{tabular}{l|l|l|lll}
\hline & $\mathbf{1 9 7 0 - 7 9}$ & $\mathbf{1 9 8 0 - 8 9}$ & $\mathbf{1 9 9 0 - 9 8}$ & $\mathbf{1 9 9 0 - 9 9}$ & $\mathbf{1 9 9 0 - 2 0 0 1}$ \\
\hline Nominal rates & 0.6582 & 0.8113 & 0.6715 & 0.7253 & 0.8601 \\
\hline Real rates & 0.7928 & 0.8964 & 0.6919 & 0.7414 & 0.8686 \\
\hline
\end{tabular}

b. 5-year windows

\begin{tabular}{l|ll|ll|lll|l|l}
\hline & $\mathbf{1 9 7 0 - 7 4}$ & $\mathbf{1 9 7 5 - 7 9}$ & $\mathbf{1 9 8 0 - 8 4}$ & $\mathbf{1 9 8 5 - 8 9}$ & $\mathbf{1 9 9 0 - 9 4}$ & $\mathbf{1 9 9 5 - 9 8}$ & $\mathbf{1 9 9 5 - 9 9}$ & $\mathbf{1 9 9 5 - 2 0 0 1}$ & $\mathbf{1 9 9 5 - 2 0 0 3}$ \\
\hline Nominal rates & 0.6748 & 0.5050 & 0.9786 & 0.8861 & 0.7231 & 0.9053 & 0.9106 & 0.9364 & 0.9422 \\
\hline Real rates & 0.8602 & 0.6880 & 0.9666 & 0.9679 & 0.7186 & 0.9025 & 0.9134 & 0.9259 & 0.9231 \\
\hline
\end{tabular}

c. EMS regimes

\begin{tabular}{l|l|l|l|l|l|l|l}
\hline & $\mathbf{0 1 / 7 0 - 0 2 / 7 9}$ & $\mathbf{0 3 / 7 9 - 0 1 / 8 7}$ & $\mathbf{0 2 / 8 7 - 0 6 / 9 0}$ & $\mathbf{0 7 / 9 0 - 1 2 / 9 1}$ & $\mathbf{0 1 / 9 2 - 1 2 / 9 2}$ & $\mathbf{0 1 / 9 3 - 1 2 / 9 3}$ & $\mathbf{0 1 / 9 4 - 1 2 / 9 8}$ \\
\hline Nominal rates & 0.6467 & 0.9369 & 0.7900 & 0.9650 & 0.7420 & 0.7879 & 0.8627 \\
\hline
\end{tabular}


Figure 1. Country-specific weights of first principal component, twelve EMU member countries (10- and 5-year windows, nominal [bars] and real [solid lines] exchange rates)
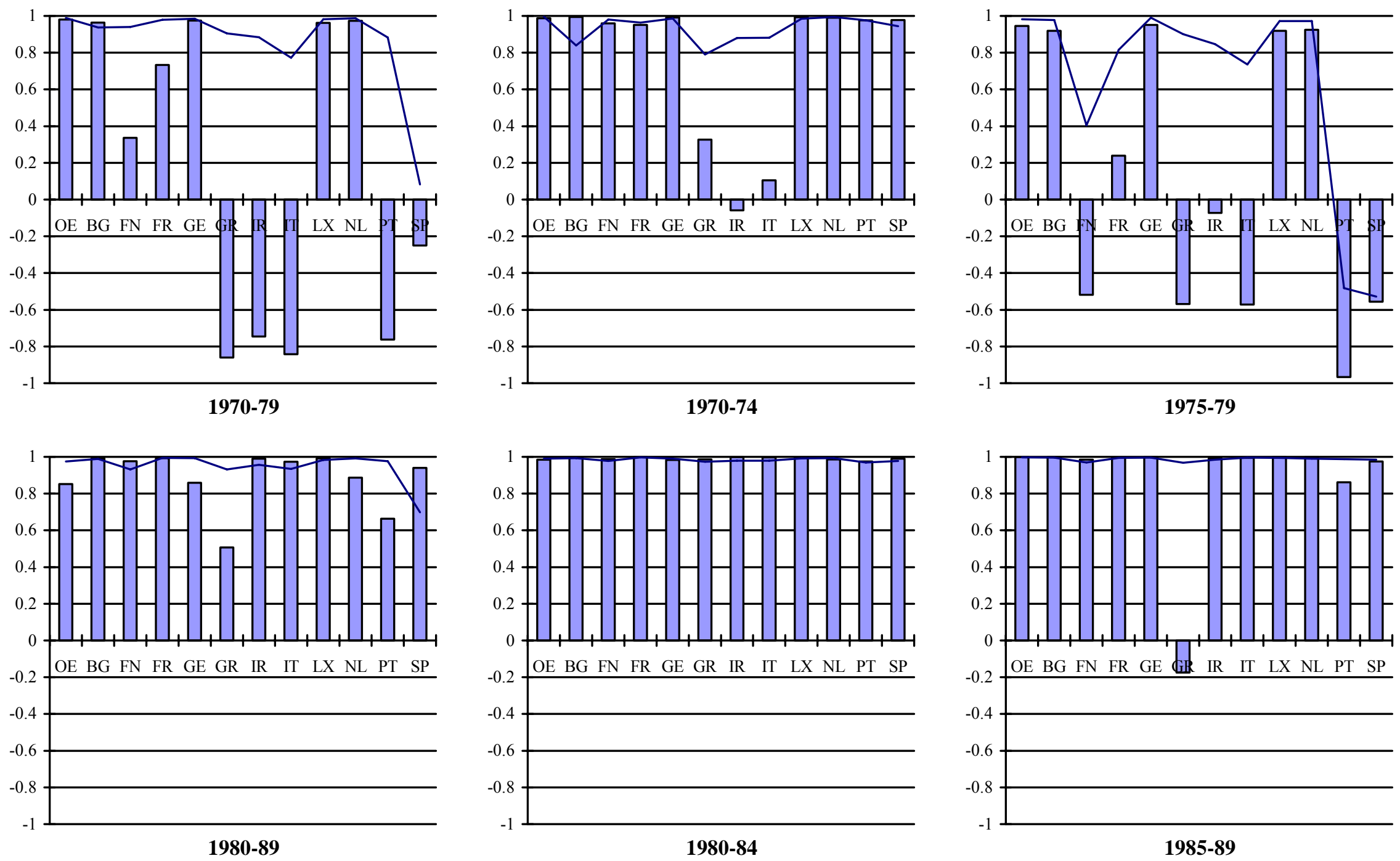
Figure 1 continued.

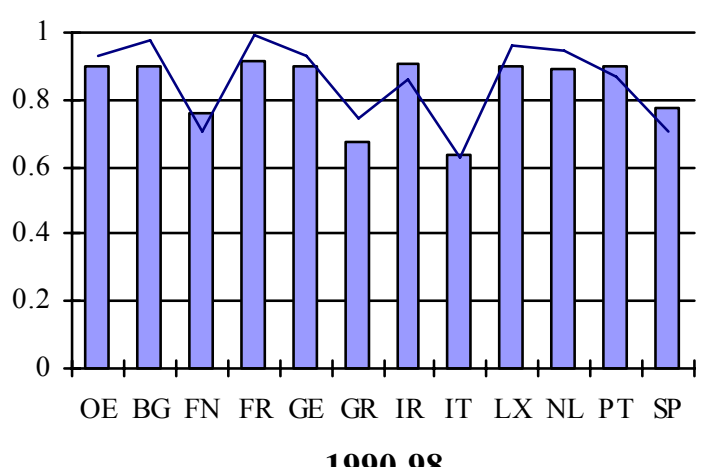

1990-98

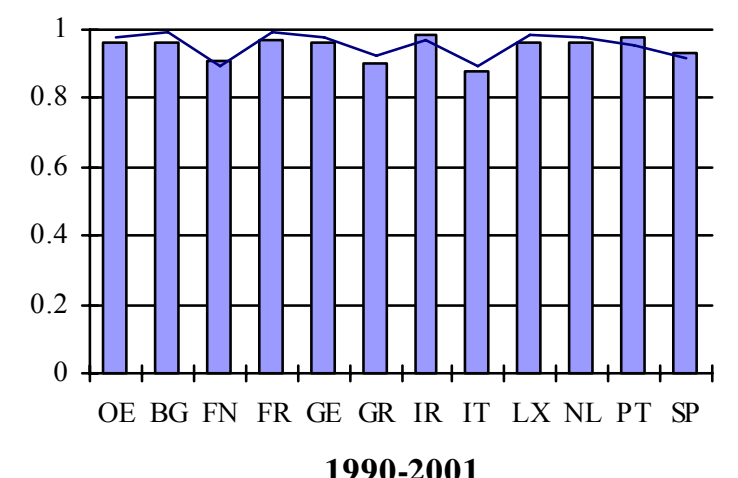

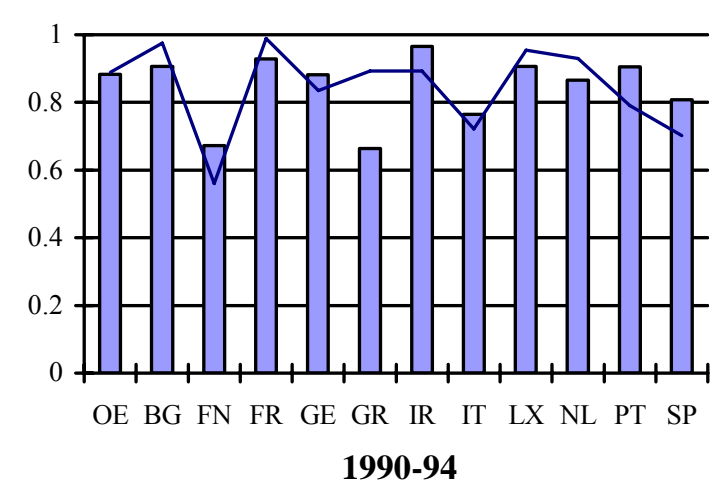

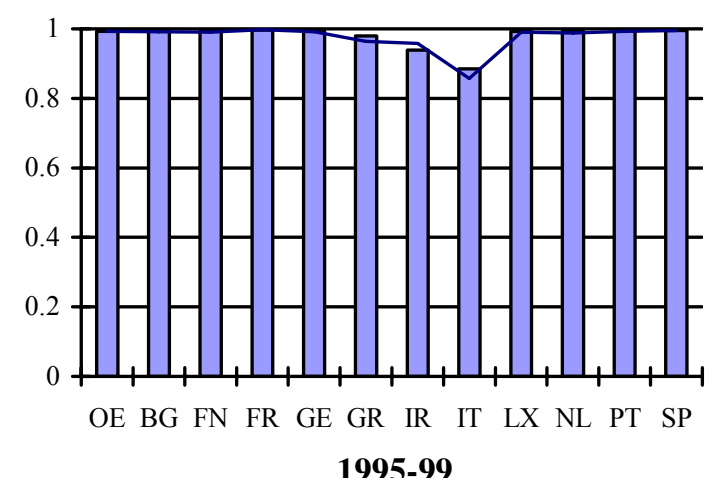

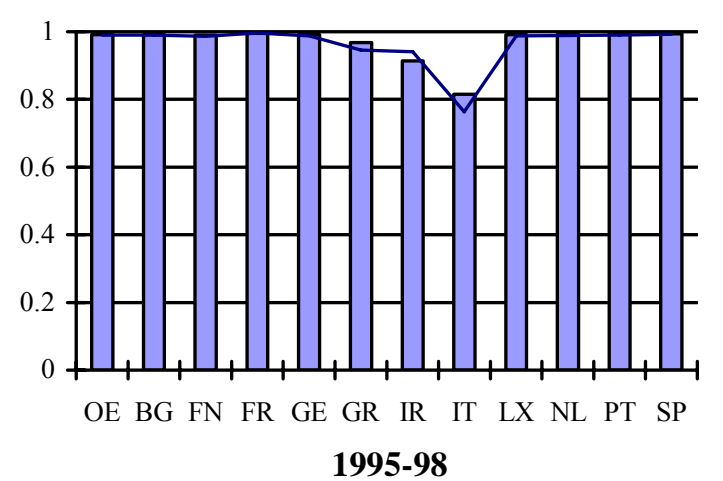

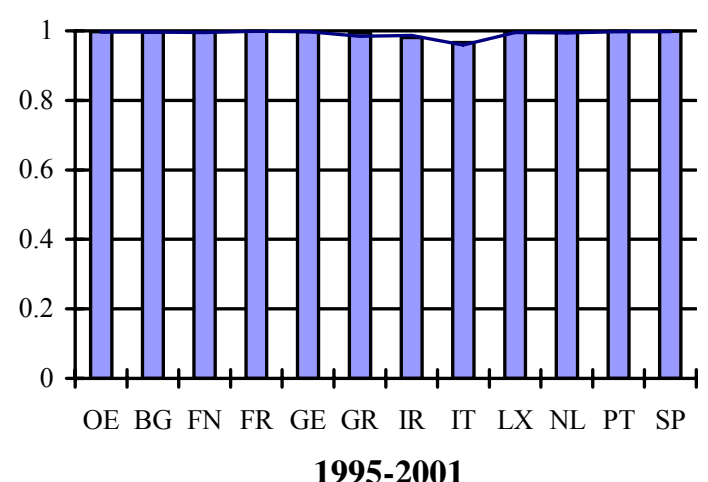

Note: The abbreviations used are: OE (Austria), BG (Belgium), FN (Finland), FR (France), GE (Germany), GR (Greece), IR (Ireland), IT (Italy), LX (Luxembourg), NL (Netherlands), PT (Portugal), SP (Spain). 
Figure 2. Country-specific weights of first principal component, twelve EMU member countries (EMS regimes, nominal exchange rates)

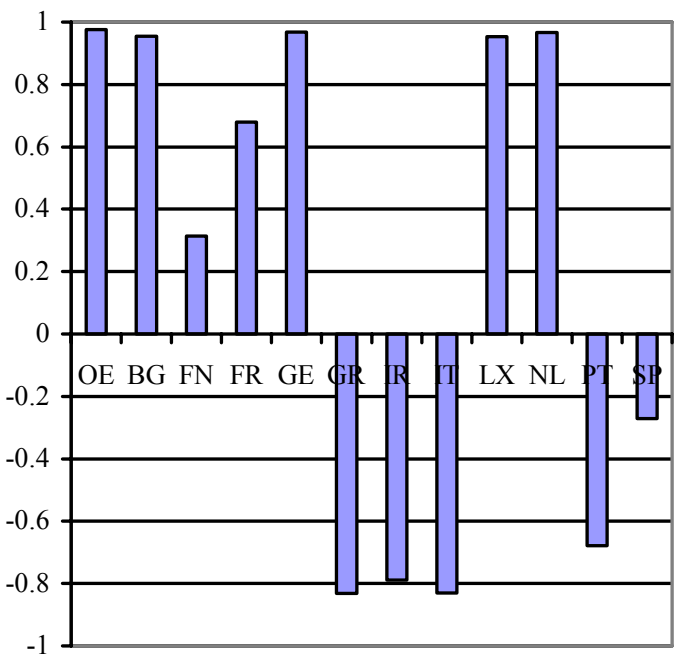

a. 01/70-02/79

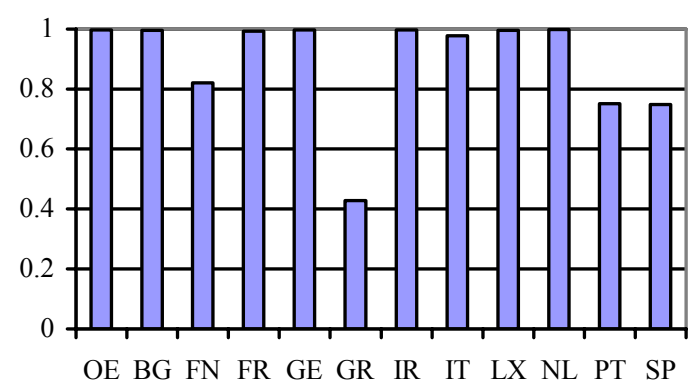

c. 02/87-06/90

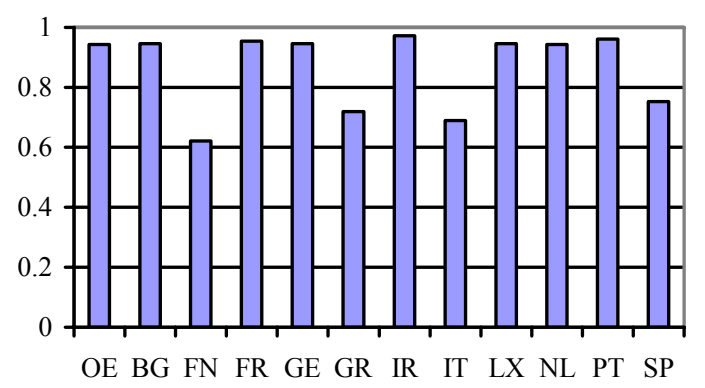

e. 01/92-12/92

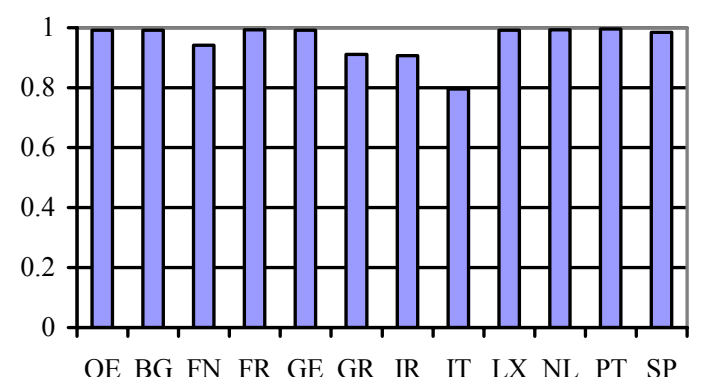

g. 01/94-12/98

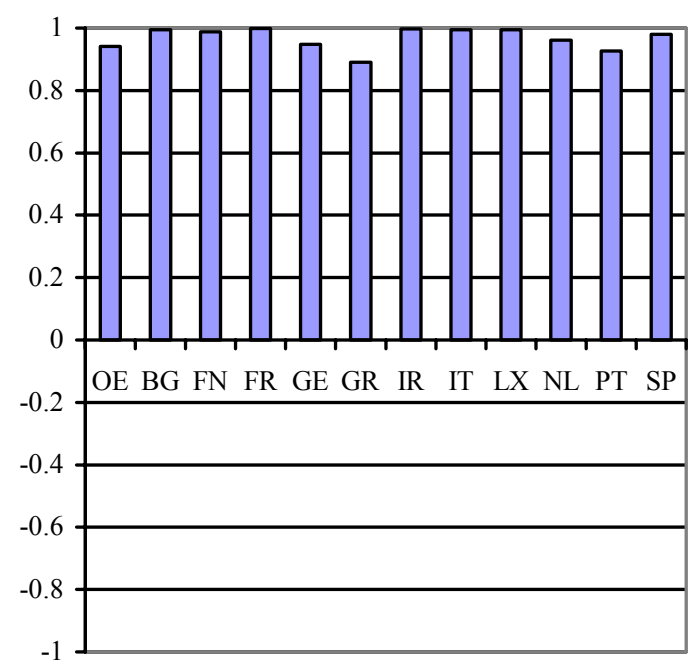

b. 03/79-01/87

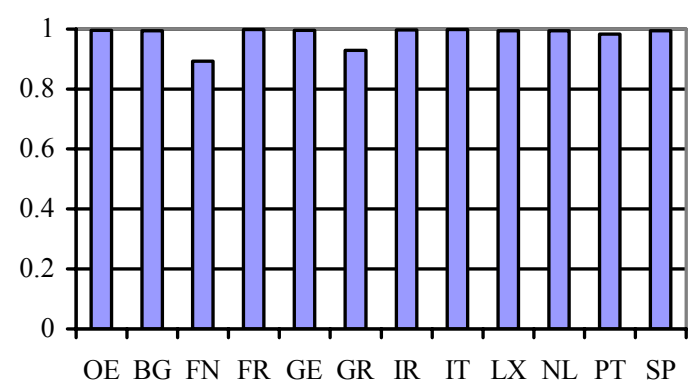

d. 07/90-12/91

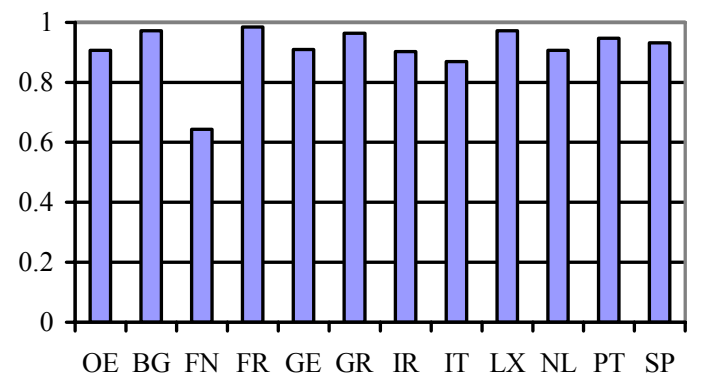

f. $01 / 93-12 / 93$ 
Figure 3. Country-specific weights of first principal component, twelve EMU member countries plus UK (nominal [bars] and real [solid lines] exchange rates)

a. 10-year windows

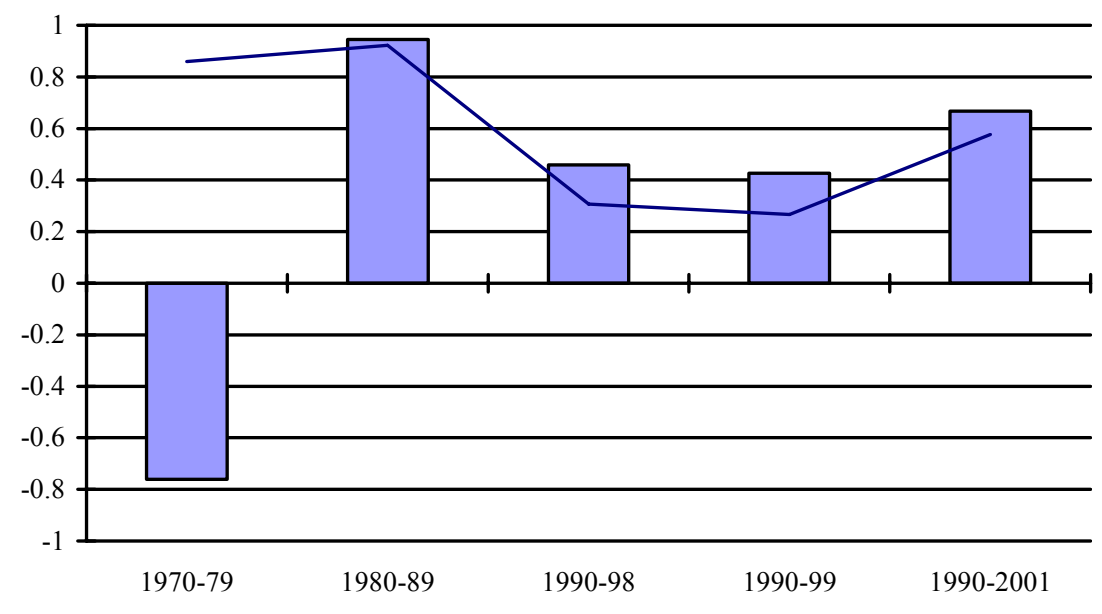

b. 5-year windows

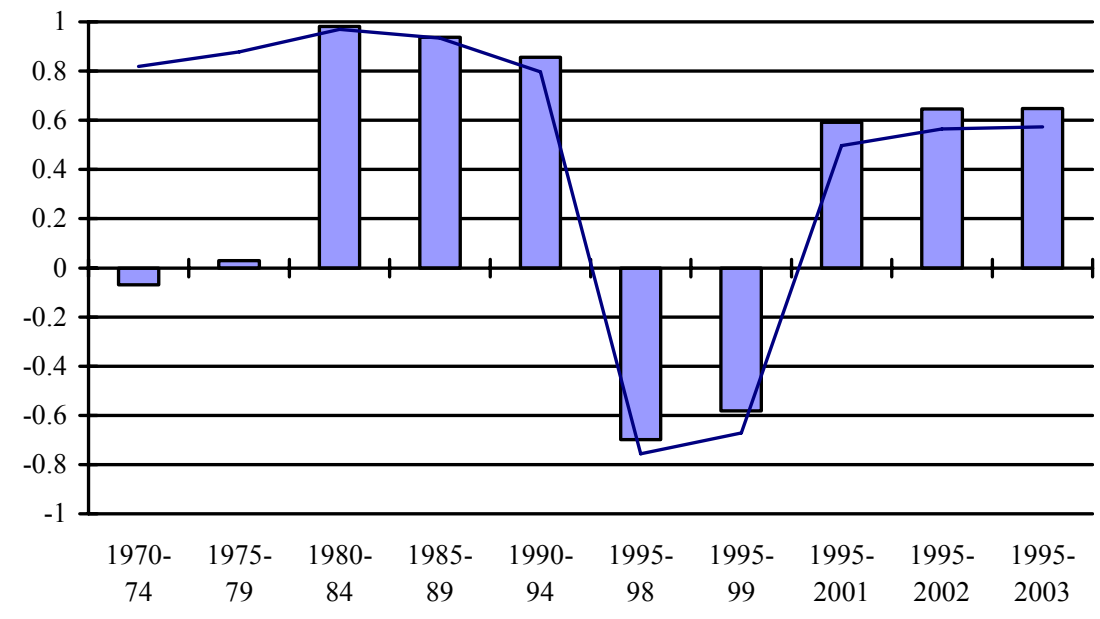

c. EMS regimes

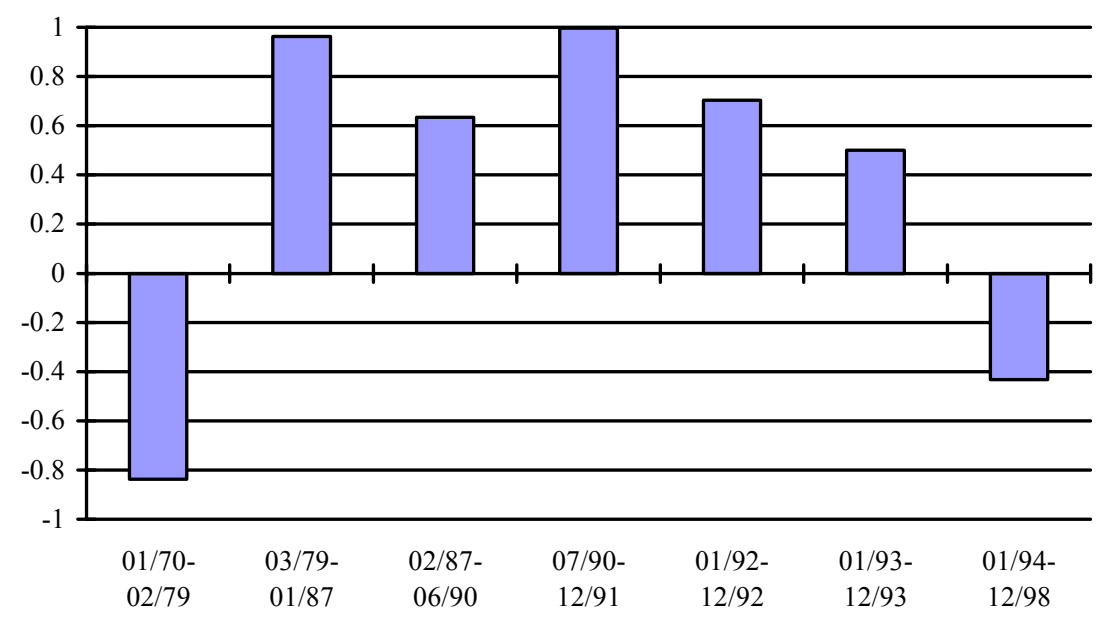

